\title{
Students' Experiences of the Teaching and Learning of Irish in Designated Disadvantaged Schools
}

\author{
Katriona O'Sullivan", Niamh Bird, Gareth Burns \\ Department of Adult and Community Education, North Campus, Maynooth University, Maynooth, Ireland \\ Email address: \\ katriona.osullivan@mu.ie (K. O’Sullivan) \\ ${ }^{*}$ Corresponding author

\section{To cite this article:} \\ Katriona O'Sullivan, Niamh Bird, Gareth Burns. Students' Experiences of the Teaching and Learning of Irish in Designated Disadvantaged \\ Schools. International Journal of Education, Culture and Society. Vol. 4, No. 5, 2019, pp. 87-97. doi: 10.11648/j.ijecs.20190405.13
}

Received: September 27, 2019; Accepted: October 12, 2019; Published: October 28, 2019

\begin{abstract}
Irish policy is increasingly focused on addressing the lack of teacher diversity. However, persistent challenges remain around the high standard of Irish required to enter primary level Initial Teacher Education (ITE) and the quality of Irish language teaching in schools that are designated disadvantaged in Ireland. This research aims to explore the relationship between these variables. Students from groups currently underrepresented in ITE and who are participating in a Foundation Course for Initial Teacher Education (FCITE) described their experiences of learning Irish in schools that are designated as disadvantaged, and then their journey through Irish language learning on the FCITE. Participants described largely negative experiences of learning Irish in school which contrasted with positive experiences of learning Irish while on the FCITE. Participants believed the communities they came from, and schools they attended, influenced the quality of teaching received; while teacher expectations of their language capabilities, and consequently their language proficiency impacted upon their Irish language learning. The findings indicate that specific measures should be put in place along the continuum of teacher education to ensure that there is an emphasis placed on not only improving the quality of Irish language teaching in schools located in communities experiencing social and economic inequality, but the parallel need to develop a model of social and political criticality amongst student and practicing teachers that addresses the problematic assumptions observed in this research about students' language learning capabilities.
\end{abstract}

Keywords: Education, Access to Higher Education, Foundation Course for Initial Teacher Education, Irish Language Teaching and Learning, Qualitative Analysis, Online Questionnaire

\section{Introduction}

The student teacher population in Ireland lacks diversity, it tends to be overwhelmingly white, female, settled, Catholic and middle-class [5]. In response to strong national and international evidence base that highlights the benefits and desirability of a more diverse and representative teaching body $[6,7]$, the Irish government have invested in the Programme for Access to Higher Education (PATH). This investment has asked universities across the island of Ireland to develop programmes which support diverse students to enter Initial Teacher Education (ITE). In this context, the academic entry requirements and the high standard of Irish language provision required for entry to ITE are considered the most significant academic barriers [8] to becoming a teacher; therefore some of the PATH funded programmes have been developed to support Irish language learning, and to examine the relationship students who are currently underrepresented in teaching have with Irish language learning. This study focuses on the Irish language learning experiences of students who come from communities experiencing social and economic disadvantage, discussing the impact that Irish language provision and Irish language learning experience across the Irish education system can have on diversifying teaching in Ireland.

Research has established close links between social class and attitudes to Irish language learning. For example, young people from higher socio-economic classes demonstrate more positive attitudes towards the Irish language than less advantaged groups [1, 2]; and for communities experiencing social and economic disadvantage, the learning of Irish is often bound up with negative memories of schooling [3]. 
Students in schools that are designated as disadvantaged (DEIS) are less likely to study higher level Irish for the Leaving Certificate than students in non-DEIS schools [4]. This has significant effects on the social mobility of students in the DEIS school system, particularly for those with aspirations to become primary school teachers, as higher level Irish language proficiency is a requirement for access to primary ITE.

While research shows that attitudes and motivations towards Irish language learning have improved among some demographic and socio-cultural groups, the promotion of Irish language learning has not been successful in areas experiencing social and economic disadvantage. There are also numerous studies that demonstrate that teachers of Irish at both primary and post-primary level experience difficulty in implementing an engaging and convincing pedagogy [915]. It has been observed that standards of teaching relating to Irish, and Irish language outcomes, are significantly worse than that of English, reading and mathematics [16].

This study aims to explore the relationships which exist between these variables. It asks a group of students from groups currently underrepresented in ITE (these groups include: those from the Irish Traveller community, students with disabilities, migrants, mature students, students studying in Further Education, and students from socio-economically disadvantaged backgrounds) and who are participating in Maynooth University's Think about Teaching Foundation Course for Initial Teacher Education (FCITE), to describe their experience with Irish language learning in school, and their journey through Irish language learning on the FCITE. By using a qualitative approach, this paper explores the complex factors which impact on the students' views of Irish language learning in the DEIS school system, contrasting this with their experience of learning language in a new context.

\subsection{Use of the Irish Language}

Despite Irish being the first official language of the Republic of Ireland in accordance with the Constitution of Ireland, and an official working language of the European Union, the majority of people in the Republic of Ireland speak English daily. As few as 3\% of people residing in Ireland reported Irish as being their mother tongue, or main household language [17], with these being mainly located in Irish language speaking communities or Gaeltachtaí [18]. The last two decades have seen significant changes in Irish society resulting in exponential growth in language diversity. Over 200 languages as well as Cant and Irish Sign Language (ISL) are now used in Ireland [19]. Recent census figures indicate that $38.7 \%$ of Irish people aged 3 and over (1.77 million) speak Irish, but only $1.8 \%(77,185)$ indicated that they spoke Irish on a daily basis outside of the education system [20]. Significantly, one in four daily speakers (25.4\%) were in the school-going age range. Research also indicates a decline in both the use and the proficiency of Irish both in Gaeltachtaí [21] and in the education system overall [9], and these figures have raised serious questions and concerns about the future of the Irish language [18].
Policy discourse around the preservation and expansion of the Irish language have largely focused on interventions within the education system [22], and these interventions are viewed as "the critical engines for generating linguistic ability" [23]. The Irish school system is the most common vehicle in which the general population are exposed to and use the language [3]. The Irish language is a compulsory subject at primary and post-primary level and is taught in three school contexts:

1. English medium schools: the majority of primary and post-primary schools in Ireland, where Irish is taught as a second language.

2. Gaeltacht schools:located in areas in Ireland where the Irish language is, or was until the recently, the main spoken language of a substantial number of the population [24]

3. Gaelscoileanna or Irish immersion schools: situated in non-Irish speaking communities, where all subjects are taught through the medium of Irish [25].

The vast majority of the general public (89\%) have a positive view of the Irish language [26] and research conducted by the Irish National Teachers' Organisation [27] showed that $65 \%$ of people felt that other subjects should be taught through Irish in primary schools to encourage children to use the language more. However, despite this, there are low level of proficiency in the language attained by many students in the education system [9-13, 16, 28-31] and this decline in proficiency amongst the school-going population is of concern, considering that this is the group who report most use of Irish on a daily basis [20].

\subsection{Motivations to Learn}

While the Irish adult population tend to display a positive attitude to the Irish language [26, 32], this positivity does not always translate into proficiency or indeed motivation. Numerous studies report low levels of motivation for learning and using Irish among students [9, 15, 33, 34, 35], and this is due to various factors. Murtagh (2007) found that motivation to learn Irish was strongly related to the language medium of the school [3]. Motivation was also strongly associated with achievement levels in spoken and written Irish. Research on primary school children's attitudes towards the Irish language in English-medium primary schools indicates some relationship between positive attitudes to the Irish language and actual proficiency [30], with children with a more positive attitude to the language demonstrating higher proficiency [30]. Furthermore, the ways in which the language is delivered impacts upon motivation to learn, and attitudes towards the language. Harris and Murtagh (1999) observed that a communicative teaching approach is strongly associated with more positive attitudes towards the language [30]. Approaches to language learning which focus on developing relevant, everyday language amongst students, and place strong emphasis on pair and group work, on role-play activities and language games; are related to positive attitudes to Irish language learning [30]. Findings like this led to the introduction of the 1999 curriculum for Irish in primary schools [37] which was 
strongly communicative in nature, aiming to enable children to use the language in daily interactions. A Primary Curriculum Review [13] found that this shift in curriculum had precipitated an increase in children's enjoyment of Irish language learning, and an increased sense of pride in the language. Despite this, McCoy, Smith, and Banks (2012) observed that primary school children's attitudes were the least positive to Irish in comparison to other curricular areas [36].

\subsection{Quality of Teaching}

There has been media commentary on the quality of Irish language teaching in Ireland [38] with two research reports showing that about a quarter of primary school teachers do not have a satisfactory standard of Irish to teach the language effectively [39, 9]. The Inspectorate of Department of Education and Skills (DES) report (2007) into Irish primary school teachers' levels of Irish proficiency offered up some worrying figures for the contexts in which students are learning Irish [11]. Twenty-three per cent of teachers were found to have unsatisfactory levels of Irish, noted as either having significant difficulties, or scope for improvement and half of all classes observed were noted as having either poor, or fair levels of teaching and learning in relation to the Irish language [11]. A link was also noted between Irish language proficiency and teaching competency with higher proficiency associated with higher levels of competence in teaching Irish, and better teaching methodologies [11]. Many teachers experience difficulty in implementing an engaging and convincing pedagogy [9-15]. While more recently it was observed that standards of teaching relating to Irish and Irish language outcomes are significantly worse than that of English, reading and mathematics [16].

Teachers impact on student motivation to learn languages $[40,41]$. In recent times teachers' attitudes to teaching and learning Irish have become more negative (9) and teacher satisfaction with teaching Irish has declined by $25 \%$. This decline correlates with students' rising dissatisfaction $(+16 \%$ increase) with learning Irish [9]. These figures are concerning, as there is a clear relationship between the selfefficacy of teachers in their own language ability and the effectiveness of their teaching [42]. Hence, teachers who have negative attitudes to the Irish language are also unlikely to create low stress and highly motivating learning contexts, factors which have been linked to greater language learning [43].

Teaching approaches across all subject areas also vary depending on school-type. Teacher-centered and structured approaches, with less use of active teaching methods, are more likely to be evident in schools designated as disadvantaged (DEIS) [44]. This is evidenced in a recent analysis of teaching approaches in DEIS schools, which found that teachers spent more time 'off task' in response to disciplinary issues [45] and that they report spending more time on English and Social, Personal and Health Education (SPHE), and less time on Irish, than those in non-DEIS schools [36]. These teachers reportedly make trade-offs between different subject areas, adjusting their timetable to reflect the perceived needs of students, prioritizing literacy and personal-social development over Irish language learning.

\subsection{Policy Responses}

In response to decreasing Irish proficiency and increasingly complex multilingual classroom environments [46], the NCCA have recently introduced a new Primary Language Curriculum (PLC) [19]. The new PLC [19] replaces the previous Primary School Irish Language Curriculum [37] which operated within a bilingual framework, and is an integrated language curriculum. The new PLC is designed to allow teachers greater flexibility, encouraging children to transfer skills acquired in one language to others [46] and enabling children to make and explore meaning as well as receive and create it [19]. Content and Language Integrated Learning (CLIL) has been defined as an educational approach where content is taught through the medium of a second language. The focus is on learning of content rather than on language. The Irish Government's 20Year Strategy for the Irish Language 2010-2030 [23] proposes to improve the proficiency in Irish of primary school pupils by offering CLIL to all pupils [38]. CLCL is also mentioned as a means of developing pupils 'literacy skills in Irish' in the highly influential National Literacy and Numeracy Strategy [48].

\subsection{Teacher Education and Irish Language Teaching}

The aforementioned 20-year Strategy for the Irish Language 2010-2030 [23] stated that effective implementation required "a focus on developing expertise and skills among the teaching profession - given the critical importance of the school in influencing language awareness and behaviour" (p.10). The recent restructuring of ITE in Ireland has facilitated the reform process, with all ITE programmes now incorporating specific modules which focus on Irish medium immersion (IMI) and bilingual pedagogy and theory [18]. In response to identified challenges around how to differentiate teaching and learning approaches in classrooms in order to cater for the specific needs of native speakers of Irish, Marino Institute of Education are due to commence a Bachelor of Education in Irish-medium Education in the 2019/2020 academic year.

There is also recognition at policy level of the need to supplement these reforms of ITE with similar reforms at each phase of the continuum of teacher education [40]. The 20 year Strategy for the Irish Language [23] points out that a National Centre for Irish-Medium Teacher Professional Development, will lead, manage, develop and support teacher education provision for the entire cycle of Irish-medium schools. Designed specifically for IMI educators and other professionals in Irish medium education, Mary Immaculate College, Limerick provides a M.Ed. in Irish-medium Education. National University of Ireland Galway provides a Professional Master of Education programme conducted 
solely through the medium of Irish for teachers working in the Irish-medium post primary sector.

\subsection{Class and Identity}

In Ireland, use of the Irish language is intrinsically linked with Irish culture and identity, explicitly stated in the introduction to the new PLC [19].

The curriculum recognises that for non-native speakers of Irish, experience and knowledge of Irish are important to enable children to define and express their understanding of national and cultural identity (p.6).

Edwards [50] notes that, "the attachment felt by the English-speaking Irish or Welsh to a culture and an ancestry whose language they no longer possess is a psychologically real one, and demonstrates the continuing power of what is intangible and symbolic". Irish has traditionally been associated with certain political and religious groups. For example, in Northern Ireland Irish language use is associated with being Republican and Catholic [2]. This association with identity and culture has an impact on individual motivations to learning Irish [2].

Research has also described a link between social class, attitudes to Irish and take up of higher-level Irish at second level education. Students from higher socio-economic classes demonstrate more positive attitudes towards the language than less advantaged groups $[1,2]$. Students in DEIS schools are less likely to study higher level Irish for the Leaving Certificate (terminal exam in Ireland) than students in nonDEIS schools [4], which in turn can have significant effects on the social mobility of DEIS students. Higher level Irish language proficiency is essential to gain access to some highstatus professions in Ireland. Entry to primary ITE requires higher level Irish at Leaving Certificate level, meaning that students in non-DEIS schools are more likely to access this profession. Until very recently, all jobs in the Irish civil service required a high level of Irish competence [51]. Furthermore, many Higher Education Institutes still require an Irish language qualification for entry - making the Irish language a form of currency in the Irish education and employment system. To-date there has been little examination of the experiences of students in the DEIS school system who aspire to move into teaching. While there is significant variation in teaching focus in DEIS schools, and there are observed differences in the attitudes towards the Irish language across social classes; there has been little or no examination of how this is experienced in the Irish classroom. The current study aims to extend this understanding by examining the Irish language learning experiences of students who come from communities experiencing social and economic disadvantage, who went to schools which are designated as disadvantaged in this context and whom aspire to become teachers. This study examines how their experience of Irish language learning in school compares to their experience of language learning in a university foundation course for ITE.

\section{Methodology}

This study aims to explore the complex relationship between attitudes and motivations towards Irish language learning and the experience of social and economic disadvantage. Using a qualitative approach, this study explores the complex factors which impact students' views of Irish language learning and their experience of learning language in a new context.

\subsection{Data Collection}

Data were collected in March of 2019 through an online questionnaire circulated to students who had been accepted onto Maynooth University's Think About Teaching programme, a Foundation course for initial teacher education (FCITE) for students from groups identified as underrepresented in ITE. The FCITE is a pilot programme funded by the PATH programme through the Higher Education Authority (HEA) of Ireland and Maynooth University. It aims to address the academic, social and personal challenges faced by underrepresented groups within the teaching profession, providing support to increase the academic confidence and capacity of students, enabling them to progress into ITE in the university [52].

Students are split into two streams based on the level they would like to teach in the future i.e. a primary level teaching stream, and a secondary level teaching stream. Participants on the primary strand of the FCITE study the module 'Cumas na Gaeilge'. This module aligns with Level B1 as specified in the Common European Framework of Reference for Languages, and aims to develop the student's necessary competence in the Irish language for entry into Primary ITE. Oral, aural, reading and written Irish-language competence are assessed through the Teastas Eorpach na Gaeilge (TEG) Meánleibhéal 1 (B1) examination.

\subsection{Participants}

Participants were students from groups currently underrepresented in ITE (including those from the Irish Traveller community, students with disabilities, migrants, mature students, students studying in Further Education, and students from socio-economically disadvantaged backgrounds) who are participating on a FCITE. All students registered on the FCITE were invited to participate in an online questionnaire through email, including students who were part of the primary level stream and the secondary level stream of the programme. All students had experiences of studying Irish at second level but only the primary level stream were currently studying Irish on the FCITE. Sixteen students agreed to participate and completed the questionnaire. Twelve of these were on the primary stream and currently studying Irish, with four participants on the second level teaching stream. All students were categorised as socio-economically disadvantaged through the FCITE application process. This considered parental occupation, education, post-code, school attended and experience of higher education in the family. 


\subsection{Questionnaire}

Demographic information was collected through an online questionnaire, including information on the gender and ethnicity of the participants. Participants were also asked two open-ended questions, one relating to their experience of learning Irish prior to starting the FCITE, and one about their experience of learning Irish on the FCITE.

\subsection{Data Analysis}

Descriptive analysis was performed on the demographic data. Thematic analysis was adopted to analyse the qualitative data. Guided by the research questions, themes and patterns within the data were identified and coded. Initial codes were refined into themes. The resulting themes were discussed in relation to the research questions.

\subsection{Ethical Approval}

Ethical approval was granted prior to data collection by the Maynooth University Research Ethics Committee. Participants were given a detailed information sheet on the project and signed a consent form before participating. Data were de-identified before analysis to protect confidentiality and participant privacy.

\section{Findings}

\subsection{Demographic Characteristics}

Three males (18.75\%) and 13 females $(81.25 \%)$ responded to the survey. Respondents were largely White Irish (12; $75 \%$ ), with two respondents reporting being from an Irish Traveller background $(2 ; 12.5 \%)$ and two reporting to be from other ethnic groups $(12.5 \%)$. Respondents were from both DEIS (12; 75\%) and non-DEIS (3; 18.75\%) schools. One respondent $(6.25 \%)$ had attended Youthreach, a Department of Education and Skills official education, training and work experience programme for early school leavers.

\subsection{Experiences of Irish Language Learning Prior to the FCITE}

Participants were asked to describe their experiences of teaching and learning of Irish prior to entering the FCITE, including their experiences of learning the Irish language within the school system. Thematic analysis revealed a number of important themes relating to both positive and negative experiences of learning Irish in the Irish school system including the influence of teachers and the language context on language learning, low levels of confidence related to learning the language and positive attitudes to the language itself.

\section{Learning context and teacher attitudes}

Negative and high stress learning contexts negatively impacting on participants' experiences of learning Irish. Participants noted learning the language in contexts where little support was provided for students who were struggling, creating a context of fear and limiting their ability to actively engage with the language in a meaningful way:

...if you didn't grasp the Irish you were left behind and not taught what you didn't understand.

Participants further added to this point noting that those who were considered "weaker" at the language were often ignored, with teachers tending to focus on those who were likely to achieve higher grades:

The teachers didn't care that some of us didn't understand it and focused on the ones doing well.

This left participants with no choice other than to try to compensate by "learning off" material limiting active engagement with the language:

I didn't understand the grammar whatsoever and learned off material in order to pass my exams.

Participants also noted that teachers held negative attitudes towards their ability to learn Irish based on their social class:

[The] teacher told me I wasn't good enough because I was from [socially and economically disadvantaged community]. She said she hated working with people like us.

Participants also noted the role that instability in their educational environments, at both primary and second level, played on their ability to learn Irish with one stating:

I didn't have that one teacher who influenced me, to help me grasp and understand the language. We had numerous substitute teachers at primary level due to teacher getting sick in $5^{\text {th }}$ and $6^{\text {th }}$ class, I think we had 7 overall and that's not an exaggeration and during secondary we changed Irish teacher every year during the junior and leaving cycle with teachers from different areas and dialects, it was difficult as there was no consistency.

This further compounded stress for students, with a lack of consistency and stability limiting their ability to engage with language learning in a meaningful way.

Given that low stress and highly motivating contexts are linked to greater language learning and learner autonomy [30], the environments described by participants in the present study are unlikely to produce positive language learning outcomes.

Teaching style and experiences of Irish language learning

Participants were critical of the way in which Irish was taught in their schools. They reported that Irish was taught in a rigid and didactic manner.

Throughout school I was only taught how to pass an exam and regurgitate sentences and phrases about poems and poetry, I never understood the grammar of the language or why certain words change under different circumstances. I felt embarrassed to speak Irish at the beginning of the course as I didn't have a lot to begin with and was afraid to mispronounce words.

Participants reported doing much of their learning through rote learning. They reported learning Irish in order to pass exams, rather than to become proficient in speaking the language:

I felt like learning Irish in school was just learning off paragraphs to write an answer for a question and not actually understanding what I was writing. I didn't feel like I learned 
any practical Irish for everyday speaking, it was just learning off stuff by heart.

I had a good enough experience with learning Irish. But had not got much confidence. I feel it was taught too regimentally. There was no flow to it. It felt like it was not natural but here the experience in this course, it's the complete opposite. Very natural and well taught.

This type of rote learning was described by many participants, who noted that despite spending many years studying the language in all its intricacies, had very little understanding of Irish grammar or practical use of the language:

Irish was extremely daunting for me, throughout school I was only taught how to pass an exam and regurgitate sentences and phrases about poems and poetry, I never understood the grammar of the language or why certain words change under different circumstances.

My experience was never good. I was never taught the language just how to learn off essays in the language...I couldn't even string a sentence together.

They also reported a lack of interest, a negative attitude amongst their teachers to teaching the Irish language and a lack of teachers, and all of these things negatively impacted on their engagement with Irish language learning.

The lack of interest in teaching the language in secondary school made it really hard to engage in it and see it as accessible to grasp.

Unfortunately I didn't have a good experience of learning Irish at both primary and secondary school, I just happen to not get teachers throughout that were able to teach me to a good level, I didn't have that one teacher who influenced me, to help me grasp and understand the language. We had numerous substitute teachers at primary level due to teacher getting sick in 5th and 6th class. I think we had 7 overall and that's not an exaggeration, and during secondary we changed Irish teacher every year during the junior and leaving cycle with teachers from different areas and dialects, it was difficult as there was no consistency.

Participants were also critical of the Irish language curriculum, particularly at second-level and a perceived lack of focus on spoken Irish:

I felt that I didn't really understand what I was saying and most of my studying consisted of just learning as much as I could of... In class I felt the curriculum to be very boring and made it difficult to study the language.

Participants revealed that the teaching styles and methods of instruction used were important influences on their Irish language learning, with negative experiences largely attributed to rote learning and didactic teaching methods which left little space for real understanding or use of the Irish language in their everyday conversations.

Levels of confidence in Irish language ability

Prior to taking part in the FCITE, many of the participants reported low levels of confidence in relation to their Irish language abilities. Even participants who reported relatively good proficiency in foreign language learning reported difficulty and low confidence in learning Irish.
Even though I was decent at other languages like French, Irish always seemed to be much harder.

Participants reported low confidence particularly in relation to their proficiency in spoken Irish above other aspects of the language. They spoke openly about fear of making a mistake when speaking Irish.

...you're speaking Irish to someone who is fluent and it's just the pressure of knowing they know a lot more and could not know what exactly you're saying because you're saying it wrong. Irish orals have always been a struggle to me since the start of secondary because I think it's just lack of confidence I have when it comes to it.

Participants indicated a concern of not knowing enough Irish to hold a conversation with someone who was proficient or fluent in the language and a perceived judgment of their levels of proficiency as a barrier to them practising and improving their spoken Irish.

Positive experiences with teachers

When participants of the FCITE described positive experiences of Irish language learning prior to commencing the FCITE, these largely related to positive experiences with individual teachers. Participants spoke of teachers who were passionate about the language and how they instilled passion in them for the language.

I had a very positive Irish learning experience. My teacher in $5^{\text {th }}$ and $6^{\text {th }}$ year was so passionate about the language and I looked up to her so much.

Positive experiences of teachers not only instilled a passion for the language in these participants but these teachers became role models, inspiring them to consider careers as teachers.

I really enjoyed learning the language from fourth class to sixth when I had a great Irish teacher. She is the one of the main people that inspired me to become a teacher. She also gave me a love of the language through the way she taught it.

We can see from the responses of participants that teachers' attitudes to the language and Irish language learning can have an impact on student motivation to learn a language. Passionate and inspiring teachers created an environment where a love of the language could grow, and create positive learning environments for participants. We can however, observe the conflicting and complex relationship between participants' attitudes to the Irish language and realised language learning outcomes emerging in the participants' responses. Despite many participants having a relatively positive attitude towards the Irish language itself, their confidence in their language learning abilities and their perceived levels of proficiency in the language are low.

\subsection{Experiences of Irish Language Learning During the FCITE}

Participants were asked to describe their experiences of learning Irish on the FCITE and how this compared to their experiences of learning the Irish language within the school system. Thematic analysis revealed a number of important themes emerged relating to overall extremely positive 
experiences of learning Irish while on the FCITE. These included: improvements in their language proficiency particularly relating to grammar and language construction, positive experiences of using and learning the language in a communicative way, increased confidence, positive teacher experiences, and positive attitudes to the language and language learning.

\section{Improvements in grammar and sentence construction}

Participants reported marked improvements in their Irish language skills particularly in relation to their understanding of the language and construction of sentences, in oral and written form.

I can make my own sentences and I have a grasp of the language. This course has taught me the language and how to use it unlike school.

Participants noted feeling like they were making up for lost time in a way, improving their grammar skills and learning aspects of the language they felt they should already have known:

I've improved so much of my grammar skills.... I feel I'm after learning lots I should have been taught as a child.

These positive outcomes in grammar and overall language ability, which participants in part credited to the learning environment, contrasted to participants' prior experiences of Irish language learning where they reported learning Irish through rote learning, and having little actual understanding or practical use of the language.

Learning and using Irish in meaningful contexts

Participants on the FCITE described how improvements in their proficiency were encouraged by learning the language through interactive and communicative methodologies that encouraged them to use the language in real and meaningful contexts.

The way the language has been taught is brilliant. Very natural. We are put in situations where we have to speak to each other.

They reported that learning the language in this way helped them to develop practical use of the language, moving away from the model of learning information for an exam. Participants described how this teaching style increased understanding and reduced fear of speaking the language and making mistakes.

I have learned more in the past year than I did within my six years of secondary school. We are not just learning enough Irish to pass an exam, we can engage in conversations, we now understand grammar rules, there isn't a fear of speaking the language.

Participants noted that taking part in the FCITE had contributed to filling in some of the gaps in their knowledge and learning of Irish that they had described prior to the course, increasing their understanding, and in turn Irish language abilities:

I learned the basics of Irish and understand now the reason why certain things are constructed the way they are.

Participants' experiences of learning Irish on the FCITE were different to their experiences of learning the language in the school context where they described teaching styles and methods of instruction which relied heavily on rote learning for the purpose of exams, leaving little space for actual practical understanding or use of the Irish language in their everyday lives or conversations. In contrast, the FCITE Irish curriculum focused on practical and spoken use of the language which made it more accessible to participants, and created a positive learning experience.

Increased confidence in language learning proficiency

Participants described how the Irish curriculum on the FCITE increased their levels of confidence in relation to Irish language learning and their own proficiency in the language. They noted that the course was accessible to all levels of Irish proficiency, starting from the basics of Irish language use, and how this impacted their confidence in using the language.

[Tutor] literally started from the beginning with us. As in what you would say to someone you met for the first time and she built on it. My confidence had grown so much.

Participants also highlighted how the communicative methodologies employed on the FCITE impacted positively on their confidence. They reported now having a broad use of the language and confidence in their abilities to speak Irish.

I have built more confidence speaking it compared to how I was before doing the course. I have learnt how to speak naturally... and my Irish vocabulary has broadened.

Participants highlighted the importance of not being afraid to speak the language or make mistakes in their spoken Irish, which contrasted with their previous experiences where they described fear associated with speaking the language:

We're not just learning enough Irish to pass an exam, we can engage in conversations, we now understand grammar rules, there isn't a fear of speaking the language.

On the FCITE, they did not experience any fear of making mistakes in their spoken Irish due to the positive and open learning environment created by the teacher.

[Tutor] is an amazing teacher and she gives you so much confidence to speak Irish, even if you make mistakes she turns it into a positive experience.

Participants reported experiencing a low stress and highly motivating context for Irish language learning on the FCITE, which is linked to positive language learning and increased learner autonomy.

\section{Positive teacher experiences}

Time and time again the participants referred back to the emphasis the teacher placed on developing positive relationships with the particpants on the FCITE. The teacher's passion, proficiency and ability to create a positive learning environment was instrumental in not only improving their Irish language proficiency, but also their love for the language.

My teacher has been excellent and has really helped me improve my grammar alongside other aspects of the language. I think that her love of the language, her belief in her students and her knowledge of the language is what makes her such a good teacher.

Those who had reported negative attitudes to Irish language learning in the past, reported how the positive 
influence of this teacher had changed their attitudes to learning Irish.

[Tutor] is brilliant. She's such a good teacher. I've improved so much of my grammar skills. Since coming on the foundation course, I have found my negative thoughts about Irish have changed to a new love for it my favourite subject is Irish now.

Participants actually enjoyed their experiences on the FCITE so much that they wanted to have more Irish classes, which was largely credited to the positive learning environment created by the teacher.

We have a fantastic teacher who I have to credit all my progress to but would've liked more hours with her.

Like those who had positive teacher experiences prior to the FCITE, we can observe that teachers' attitude to the language and Irish language learning can impact on student motivation to learn a language. A teacher who is passionate and can create a low stress, highly motivating environment not only improves language proficiency but also encourages a love and passion for the language.

\section{Discussion}

Participants in this study described largely negative experiences of Irish language learning prior to the FCITE in relation to learning contexts and experiences with teachers. Teachers had low expectations of their learning abilities which they related to teachers' negative assumptions relating to students' social class. Learning environments described by participants were observed to be negatively associated with language learning outcomes. A consistent theme emerging from participants' responses was their belief that their social class, the communities they came from, and the schools they attended; influenced the quality of teaching received, teacher expectations of their language capabilities, and consequently their language proficiency. These negative experiences and unchallenged negative teacher assumptions that underpinned them has the power to impact the social mobility of students in terms of education and employment [51]. Therefore, students from marginalised backgrounds are further disadvantaged in terms of their social mobility in relation to Irish language learning.

Participants revealed that the teaching styles and methods of instruction used were important influences on Irish language learning. They were particularly critical of the practice of learning Irish through rote learning. In their experiences, this left little space for meaningful understanding or use of the language in their everyday lives or conversations. The participants' perceptions of their own levels of Irish proficiency reflect previous research which indicates that levels of proficiency in Irish schools is on the decline (9). In contrast, participants reported experiencing a low stress and highly motivating context for Irish language learning on the FCITE, which is linked to positive language learning and increased learner autonomy. In contrast to their previous experiences of learning Irish, participants indicated that the Irish curriculum on the FCITE focused on practical and spoken use of the language which made it more accessible to the participants, and created a positive learning experience. This is in line with previous research which indicates that a communicative teaching approach is strongly associated with more positive attitudes towards the language [30] and increased student enjoyment of learning the language [13]

Participants also reported a perceived lack of interest, or negative attitudes amongst their teachers to teaching Irish which negatively impacted on their engagement with Irish language learning. Previous research has indicated that teachers who have a negative attitude to language learning are less likely to create the low stress and highly motivating contexts [43]. Where participants reported positive experiences of Irish language learning prior to the FCITE, these related largely to positive experiences with individual teachers. This was replicated on the FCITE, where all participants reported positive relationships with the tutor. Responses indicate that teachers' personal attitudes to the language and Irish language learning impacts on student motivation to learn a language. Passionate and inspiring teachers create an environment where a love of the language can develop and create positive learning environments for participants. Given that participants reported more positive learning outcomes with teachers who displayed a more positive attitude to Irish language learning, it is concerning that research indicates that teacher satisfaction with teaching Irish has declined by $25 \%$ in recent years (9).

\section{Conclusions}

Results of this study paint a worrying picture for Irish language learning in Ireland, particularly in the case of students attending DEIS schools. It is imperative that all students have a positive experience of learning Irish as Irish proficiency is intrinsically linked with social class and status in Ireland, having the power to impact the social mobility of students in terms of education and employment; and act as a barrier to accessing high status professions including primary school teaching. In light of the recent policy response to the lack of teacher diversity in Irish schools, it is important that an increased emphasis is placed on improving the engagement of students in DEIS schools with the language, and how this impacts negatively on the number of students studying Irish at higher level and thus progressing to ITE. Considering the recent policy response to persistent challenges around the quality of Irish teaching in Irish schools, findings indicate that specific measures should be put in place at ITE and right along the continuum of teacher education to ensure that there is an emphasis placed on the improving the quality of Irish language teaching in English medium schools, and particularly those servicing communities experiencing social and economic inequality. Recent curriculum changes at primary level, and pedagogical advances around the benefits of using CLIL in terms of developing students' literacy skills in Irish offer exciting opportunities in this regard. However, current teacher shortages, particularly in the area of Irish language teaching at 
second level, threatens to undermine the quality of education at primary and post-primary levels, and in particular for those attending DEIS schools, where shortages are most acutely experienced. The findings also strongly point to the need to develop a model of social and political criticality amongst student and practicing teachers that addresses problematic assumptions about students Irish capabilities in communities experiencing inequality [44].

The positive engagement that the FCITE students had with the Irish language while studying the TEG curriculum highlights the need to discuss the current second level curriculum and the benefits of all students studying a syllabus that is based on the Common European Framework of Reference of Languages [53]. As De Spáinn [54] highlights, such an approach would allow students to 'learn language skills with clear communicative objectives, starting with an increased emphasis on oral and aural skills and progressing to more advanced written skills as the student progresses through the framework'. Such an approach would have the added advantage of ensuring that all students would study and be assessed at the level of their own personal ability instead of the rigidness of the present system.

\section{Recommendations}

In light of our knowledge of how Irish proficiency is intrinsically linked with social class and status in Ireland, and with its power to impact the social mobility of students through determining education outcomes, the authors recommend that Irish education policy should immediately address the lack of teacher diversity in Irish schools by examining how Irish language learning happens in schools designated as disadvantaged. Furthermore, we recommend that access programmes such as the FCITE discussed in the present study, which targets underrepresented groups in teaching, should be extended as they provide an alternative route into teaching and help to improve students' experiences with Irish language learning.

It is imperative that an increased emphasis is placed on improving the engagement of students in DEIS schools with the Irish language, as this has a direct impact on the number of students studying Irish at higher level. Findings indicate that specific measures should be put in place along the continuum of education to ensure that there is an emphasis placed on improving the quality of Irish language teaching in English medium schools, and particularly those servicing communities experiencing social and economic inequality.

It is recommended that teaching pedagogies should continue to adopt CLIL practices as a means of developing and improving students' literacy skills in Irish. However, in order to do so, they must consider practical difficulties such as teacher shortages. These barriers threaten to undermine the quality of education at primary and post-primary levels, particularly for those attending designated disadvantaged schools, where shortages are most severely experienced.

As already stated, findings also strongly point to the need to develop a model of social and political criticality amongst student and practicing teachers that addresses problematic assumptions about students' Irish capabilities in communities experiencing inequality. This must happen in ITE and right along the continuum of teacher education, to ensure that these assumptions do not go unchallenged, and therefore limit the capabilities of students attending schools within communities which are experiencing social and economic inequality.

In light of the positive engagement that the FCITE students had with studying the TEG curriculum, it is recommended that a discussion needs to happen regarding the current second level curriculum. It is recommended that all students may benefit from studying a syllabus that is based on the Common European Framework of Reference of Languages (Council of Europe, 2001).

\section{Conflict of Interest Statement}

We, the authors, have no conflict of interest to declare.

\section{References}

[1] Committee on Irish Language Attitudes Research (CILAR). 1975. Report. Dublin: Stationery Office.

[2] Ó Riagáin, P. 2007. "Relationships Between Attitudes to Irish, Social Class, Religion and National Identity in the Republic of Ireland and Northern Ireland." International Journal of Bilingual Education and Bilingualism 10 (4): 369-393. http://doi.org/10.2167/beb450.0.

[3] Murtagh, L. 2007. "Out-of-School Use of Irish, Motivation and Proficiency in Immersion and Subject-only Postprimary Programmes." International Journal of Bilingual Education and Bilingualism 10 (4): 428-453. doi: 10.2167/beb453.0.

[4] Smyth, E., S. McCoy, S., and G. Kingston, G. 2015. Learning from the Evaluation of DEIS. Dublin: Economic and Social Research Institute.

[5] Keane, E., \& Heinz, M. 2016. "Excavating an injustice?: nationality/ies, ethnicity/ies and experiences with diversity of initial teacher education applicants and entrants in Ireland in 2014. European Journal of Teacher Education 39 (4): 507527.

[6] Burns, G. 2018. "Teachers from Diverse Backgrounds: 'Making a Different Kind of Difference'." International Conference on Engaging Pedagogy DCU, St Patrick's Campus, 1-19. http://icep.ie/paper-template/?pid=226.

[7] Villegas, A., and J. Irvine. 2010. "Diversifying the Teaching Force: An Examination of Major Arguments." The Urban Review 42: 175-192.

[8] Keane, E., \& Heinz, M. 2015. "Diversity in Initial Teacher Education in Ireland: The Socio-Demographic Backgrounds of Postgraduate Post-Primary Entrants in 2013 and 2014" Irish Educational Studies 34 (3): 281-301.

[9] Harris, J., P. Forde, P. Archer, S. Nic Fhearaile, and M. O'Gorman. 2006. Irish in Primary-Schools: Long-Term National Trends in Achievement. Dublin: DES. 
[10] Department of Education and Skills. (DES). 2005. Beginning to Teach: Newly Qualified Teachers in Primary Schools. Dublin: Stationery Office.

[11] Inspectorate of Department of Education and Science. (DES). 2007. Irish in the Primary School. Dublin: Inspectorate of DES.

[12] Mac Donnacha, S., F. Ní Chualáin, A. Ní Shéaghdha, and T. Ní Mhainín. 2005. Staid Reatha na Scoileanna Gaeltachta: A Study of Gaeltacht schools 2004. Dublin: An Chomhairle um Oideachas Gaeltachta agus Gaelscolaíochta.

[13] National Council for Curriculum and Assessment. (NCCA). 2008. Primary Curriculum Review, Phase 2: Final Report and Recommendations. Dublin: NCCA.

[14] Ní Shéaghdha, A. 2010. Taighde ar dhea-chleachtais bhunscoile $i$ dtaca le saibhriú/sealbhú agus sóisialú teanga do dhaltai arbh $i$ an Ghaeilge a gcéad teanga. Dublin: An Chomhairle um Oideachas Gaeltachta agus Gaelscolaíochta.

[15] Ó Duibhir, P. 2009. "The Spoken Irish of Sixth Class Pupils in Irish Immersion Schools.” PhD diss, Trinity College, Dublin.

[16] Inspectorate of Department of Education and Skills. 2013. Chief Inspector's Report 2010-2012. Dublin: Inspectorate of DES.

[17] European Commission. (2012). "Europeans and their Languages. Special Eurobarometer 386." Accessed 15 June 2014 at http://ec.europa.eu/public_opinion/archives/ebs/ebs 386 en.pdf.

[18] Ó' Ceallaigh, T. J., and Ní Dhonnabháin, A. 2015. "Reawakening the Irish Language through the Irish Education System: Challenges and Priorities." International Electronic Journal of Elementary Education 8 (2), 179-198.

[19] National Council for Curriculum and Assessment. (NCCA). 2015. Primary Language Curriculum. Dublin: NCCA.

[20] Central Statistics Office. 2011. Census 2011 Profile 9 What We Know - Education, Skills and the Irish Language. Central Statistics

Office. http://www.cso.ie/en/census/census2011 reports/census2011pro file9whatweknow-educationskillsandtheirishlanguage/.

[21] Ó Giollagáin, C., and S. Mac Donnacha. 2008. "The Gaeltacht Today." In A New View of the Irish Language, edited by C. Nic Pháidín and S. Ó Cearnaigh, 108-120. Dublin: Cois Life.

[22] Harris, J. 2007. "Bilingual Education and Bilingualism in Ireland North and South." International Journal of Bilingual Education and Bilingualism 10 (4): 359-368. doi: 10.2167/beb449.0.

[23] Government of Ireland. (2010). 20 Year Strategy for Irish 2010-2030. Dublin: Government of Ireland. http://www.ahg.gov.ie/ie/Straiteis20BliaindonGhaeilge2010 2030/Foilseachain/Strait\%C3\%A9is\%2020\%20Bliain\%20$\% 20$ Leagan\%20Gaeilge.pdf.

[24] Údarás na Gaeltachta. 2019. "Gaeltacht Locations and Profiles." Accessed July 28 2019. http://www.udaras.ie/en/anghaeilge-an-ghaeltacht/an-ghaeltacht/.

[25] Parsons, C. E., and F. Lyddy. 2015. "A Longitudinal Study of Early Reading Development in Two Languages: Comparing Literacy Outcomes in Irish Immersion, English Medium and Gaeltacht Schools." International Journal of Bilingual
Education and Bilingualism, 1-19. doi: 10.1080/13670050.2015.1019412.

[26] MORI Ireland. 2005. Turning On and Tuning In to Irish Language Radio in the 21st Century. Dublin: MORI Ireland. https://www.ipsosmori.com/Assets/Docs/Archive/Polls/irish_language_survey_j an_05.pdf.

[27] Irish National Teachers' Organisation. (INTO). 2010. 61\% in support of Irish as a compulsory subject. Accessed 26 August 2019, http://cnmg.ie/index.php?route=news/board/viewandnews_id= 3.

[28] Harris, J. 1988. "Spoken Irish in the Primary School System." The International Journal of the Sociology of Language, 70: 69-87.

[29] Harris, J. 1991. "The Contribution of Primary Schools to the Maintenance of Irish." In Ethnic Minority Languages and Education, edited by S. Kroon and Jaspaert, K. (Eds.). Amsterdam: Swets and Zeitlinger.

[30] Harris, J., and L. Murtagh. 1999. Teaching and Learning Irish in Primary School: A Review of Research and Development. Research Report 25. Dublin: Institiúid Teangeolaíochta Éireann.

[31] Péterváry, T, B. Ó Curnáin, C. Ó Giollagáin,, and J. Sheahan. 2014. Iniúchadh ar an gcumas dátheangach: An sealbhú teanga i measc ghlúin óg na Gaeltachta. Dublin: An Chomhairle um Oideachas Gaeltachta agus Gaelscolaíochta.

[32] Hickey, R. 2009. "Language use and attitudes in Ireland: A preliminary evaluation of survey results." In B. Ó Catháin (Ed.). Sochtheangeolaiocht na Gaeilge, Léachtai Cholm Cille, $39,62-89$.

[33] Department of Education and Skills. (DES). 2015. Review of Education in the Gaeltacht: Review of National Literature. Dublin: DES.

[34] Ó Giollagáin, C., Mac Donnacha, S., Ní Chualáin, F., Ní Shéaghdha, A. and O' Brien, M. 2007. Comprehensive Linguistic Study of the Use of Irish in the Gaeltacht: Principal Findings and Recommendations. Dublin: Brunswick Press.

[35] Ó Giollagáin, C. and M. Charlton. 2015. The update to the comprehensive linguistic study on the usage of Irish in the Gaeltacht: 2006-2011. Na Forbacha, Galway: Údarás na Gaeltachta.

[36] McCoy, S., E. Smyth, and J. Banks. 2012. The Primary Classroom: Insights from the Growing Up in Ireland Study. Dublin: ESRI.

[37] National Council for Curriculum and Assessment. (NCCA). 1999. Primary School Curriculum. Dublin: Stationery Office.

[38] Ó Duibhir, P. 2016. "Foghlaim chomhtháite ábhar agus teanga i gclár oideachais tosaigh do mhúinteoirí bunscoile." TEANGA 24: Bliainiris na Teangeolaiochta Feidhmí in Éirinn (24). pp. $1-14$.

[39] Department of Education and Skills. (DES). 2007. Irish in the Primary School. Dublin: Stationery Office.

[40] Dörnyei, Z. 2005. The Psychology of the Language Learner: Individual Differences in Second Language Acquisition. 1st ed. New York: Routledge. 
[41] Williams, M., and R. L. Burden. 1997. Psychology for Language Teachers: A Social Constructivist Approach. Cambridge: Cambridge University Press.

[42] Andrews, S., 2001. The language awareness of the L2 teacher: Its impact upon pedagogical practice. Language awareness, $10(2-3)$, pp.75-90

[43] Dörnyei, Z., and K. Csizér. 1998. "Ten Commandments for Motivating Language Learners: Results of an Empirical Study." Language Teaching Research 2 (3): 203-229. doi: $10.1177 / 136216889800200303$

[44] Burns, G. 2016. "Pedagogies of Sameness and Care: The Daily Practices of Early Career Primary Teachers in DEIS schools." Irish Teachers' Journal 4 (1): 93-111.

[45] Banks, J., M. Shevlin, and S. McCoy. 2012. "Disproportionality in Special Education: Identifying Children with Emotional Behavioural Difficulties in Irish Primary Schools." European Journal of Special Needs Education 27 (2): 219-235. doi: 10.1080/08856257.2012.669111.

[46] Ó Duibhir, P. and Cummins, J. 2013. Towards an Integrated Language Curriculum in Early Childhood and Primary Education (3-12 years). Dublin: NCCA.

[47] Department of Education and Skills. (DES). 2011. Literacy and Numeracy for Learning and for Life: The National Strategy to Improve Literacy and Numeracy among Children and Young People 2011-2020. Dublin: Stationery Office. https://www.education.ie/en/Publications/PolicyReports/lit_num_strategy_full.pdf.

[48] Teaching Council of Ireland. 2011. Teaching Council Policy on the Continuum of Teacher Education. Dublin: Teaching Council of Ireland.

[49] Edwards, J. (2009). Language and Identity. Cambridge: Cambridge University Press.

[50] Watson, I., and M. Nic Ghiolla Phádraig. 2011. "Linguistic Elitism: The Advantage of Speaking Irish Rather than the Irish- Speaker Advantage." The Economic and Social Review 42 (4): 437-454.

[51] O' Sullivan, K. and G. Burns, 2018. "Turn to Teaching: Diversifying Initial Teacher Education.” In: Ireland's Yearbook of Education 2018, 2019, edited by Brian Mooney, 33-37. Dublin: Education Matters.

[52] Council of Europe. Council for Cultural Co-operation. Education Committee. Modern Languages Division, 2001. Common European Framework of Reference for Languages: learning, teaching, assessment. Cambridge University Press.

[53] de Spáinn, J. 2016. A Vision for the Irish Language: Transforming the Teaching of Irish and other Languages. In: Ireland's Yearbook of Education 2018, 2019, edited by Brian Mooney, 33-36. Dublin: Education Matters. 